\section{Predicting the effect of climate change on tree species abundance and distribution at a regional scale}

\author{
Attorre $F^{*(1)}$, Francesconi $F^{(1)}$, Scarnati $L^{(1)}$, De Sanctis $M^{(1)}$, Alfò $M^{(2)}$, \\ Bruno $F^{(1)}$
}

The elaboration of conservation strategies at regional scale, dealing with the potential effects of climate change on the abundance and distribution of tree species, should be supported by models produced at the appropriate scale. We used a bioclimatic model aimed at analysing the large-scale effects of climate change on the abundance and distribution of tree species with respect to their chorological and ecological characteristics. Abundance data for 16 species, sampled in 912 plots, distributed on a $3 \times 3 \mathrm{~km}$ grid were used. A climatic model provided high resolution current climatic surfaces and a climatic scenario for 2080 was obtained using the A1FI emission scenario of HadCM3 GCM. A deterministic Regression Tree Analysis (RTA) and Multiple Linear Regression (MLR) were applied in order to define the realised niche of the species in relation to the chosen environmental variables. The comparison between RMSE values showed that RTA always outperforms MLR, in terms of predicting species distribution. Zonal species were better predicted than rare species (extrazonal or with specific habitat requirements). Climate change is expected to determine a general increase of the average potential altitude. Only the Mediterranean species are likely to be favoured by the predicted climate change, while for the two other chorological types (Sub-Mediterranean and Eurosiberian) the response seems to be species-specific, depending on the ecological characteristic of each species: the more thermophilous and xerophilous species should benefit from the predicted drought in terms of area and mean abundance, while mesophilous species should suffer a strong reduction.

Keywords: Climate change, Tree species, Central Italy, Potential distribution maps, Regional scale, Regression tree analysis

\section{Introduction}

The effects of climate change on ecosystems are already noticeable (Parmesan \& Yohe 2003, Root et al. 2003) and must be addressed as they can negatively influence the survival capacity of species. Recently, global warming has been shown to be one of the most serious threats to biodiversity (Midgley et al. 2002, Thomas et al. 2004, Malcolm et al. 2006, Thuiller et al. 2006)

\footnotetext{
(1) Department of Plant Biology, "La Sapienza" University of Rome, p.le A. Moro 5, I-00185 Rome (Italy); (2) Department of Statistics, "La Sapienza" University of Rome, p.le A. Moro 5, I-00185 Rome (Italy)

*Corresponding Author: Fabio Attorre (fabio.attorre@uniroma1.it).

Received: Jul 18, 2007 - Accepted: Aug 13, 2008

Citation: Attorre F, Francesconi F, Scarnati L, De Sanctis M, Alfò M, Bruno F, 2008. Predicting the effect of climate change on tree species abundance and distribution at a regional scale. iForest 1: 132-139 [online: 2008-08-27] URL: http://www.sisef.it/iforest
}

future distribution at a regional scale. Moreover, this approach may lead to interesting and useful information on the distribution of tree species along direct environmental gradients. The location of the study area is noteworthy. In fact, Central Italy is a crossroads for the Eurosiberian, Mediterranean and South-East European chorological types that characterise the Mediterranean basin; it is also surrounded by two seas and is characterised by a central mountainous chain. Under the light of the above reasons, the following hypotheses were investigated in this work:

- Will the expected increase in average altitude of species' range in the area considered be one of the main effects of climate change?

- Do species belonging to the same chorological type respond in a similar way?

- Is it possible to explain the responses of the species using their Ellenberg's temperature and moisture scores (Ellenberg et al. 1992)?

\section{Material and methods}

\section{Study area}

The study area consists of two Italian regions (Lazio and Abruzzo) located in Central Italy between the Tyrrhenian and Adriatic coasts and covers about $28000 \mathrm{~km}^{2}$ (Fig. 1). The area is characterised by strong climatic, topographical and geological variability. The coastal areas are characterised by a Mediterranean climate, while the inner part has a temperate climate, with an Alpine-type climate only in the highest peaks (Gran Sasso mountain, $2912 \mathrm{~m}$ a.s.1.).

Forests, following the FAO forest definition (FAO 2001), currently occupy an area of about $6720 \mathrm{~km}^{2}$. Since the end of the Second World War, the forested areas have increased because of the abandonment of traditional silvicultural activities, especially in the Apennine mountains (Falcucci et al. 2007). Evergreen forests of Quercus ilex and $Q$. suber (the latter only along the western Tyrrhenian side) potentially occupy the lowland areas along the coasts, while the inner hills are characterised by deciduous forest (Q. cerris and $Q$. pubescens). The sub-mountain and mountain belts are respectively dominated by Ostrya carpinifolia and Fagus sylvatica woods.

\section{Data set}

The data source for this study was the IN.DE.FO. of Italy for the study area (Allavena et al. 2000). It comprises 912 plots collected on the vertices of a $3 \times 3 \mathrm{~km}$ grid. The data were summarised for individual forest plots to calculate an Importance Value (IV) as a measure of abundance for each species ac- 


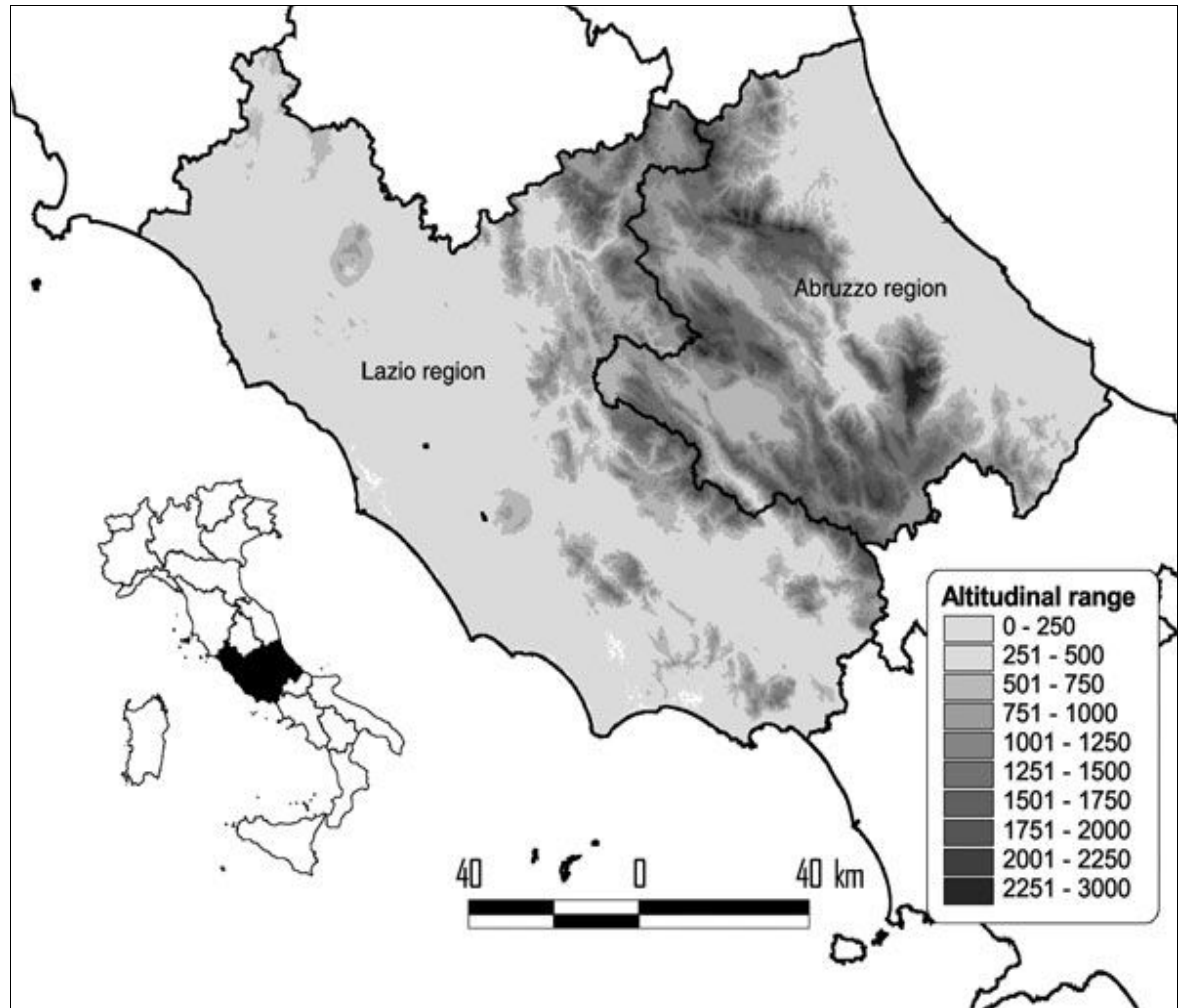

Fig. 1 - The study area.

cording to the following formula:

$$
\begin{gathered}
I V_{x}=\text { Density }_{x}+\text { Dominance }_{x} \\
\text { Density }_{x}=100 * N S_{x} / N S_{\text {all species }} \\
\text { Dominance }_{x}=100 \cdot B A_{x} / B A_{\text {all species }}
\end{gathered}
$$

where $x$ is one of the considered species, $N S$ is the number of stems of a plot and $B A$ is the basal area of the plot calculated using the diameter at breast height of each one of the stems. In monotypic stands, the IV could reach a maximum of 200.

We analysed sixteen species that are the most abundant in the study area: Acer campestre, Acer obtusatum, Acer pseudoplatanus, Carpinus betulus, Carpinus orientalis, Castanea sativa, Fagus sylvatica, Fraxinus ornus, Quercus cerris, Quercus frainetto, Quercus ilex, Quercus pubescens, Quercus robur, Quercus suber, Ostrya carpinifolia, Ulmus minor. The species listed above belong either to Mediterranean (M - 2 species), Sub-Mediterranean (SM - 8 species) or Eurosiberian (E - 6 species) chorological types (see Tab. 2 - Pignatti 1982). In order to explain the response of the species to climate change, Ellenberg's indicator values (Ellenberg et al. 1992), revised for Italy by Pignatti (2005), for temperature and moisture were used. These indicator values describe the ecological optima for the species along ecological gradients using an or- dinal scale, i.e., temperature: 1 (cold, alpine environment) to 12 (hot, subdesertic environment); moisture: 1 (dry environment, arid soil) to 12 (water environment).

\section{Environmental variables}

Very high resolution (30 arc-seconds) current climatic surfaces were obtained by interpolating climatic data (average of the 1961-1991 period) from 210 stations for precipitation and 151 for temperature through universal kriging (i.e., simple kriging with trend function defined on the basis of a set of co-variates) that has been proven to produce reliable estimates at a regional scale (Attorre et al. 2007). Future projections for 2080 (midpoint of the period 2070-2099) were derived using one general circulation model experiment (HadCM3 - Mitchell et al. 2004). The GCM projected the mean climate under one rather extreme scenario: the Intergovernmental Panel on Climate Change Special Report on Emissions Scenarios (IPCC SRES) A1FI storyline (Nakicenovic \& Swart 2000). Current and projected climatic data were obtained from HadCM3 runs. The difference between the current and future climate was calculated. The difference was statistically downscaled to a 30 arc second using the "thin plane spline" spatial interpolation (Mitasova \& Mitas 1993). The values were then applied to the measurements of the current climate to produce very high resolution climatic scenario.
Climatic data which influence plant survival and growth were chosen: mean annual temperature, mean minimum temperature of the coldest month, mean maximum temperature of the hottest month, annual, summer and winter precipitations. Moreover, a moisture index was used based on the following formula:

$$
M_{i}=P / E T p
$$

where $P$ is the mean annual precipitation, and ETp is the potential evapotranspiration; ETp has been calculated using the JensenHaise equation (Jensen \& Haise 1963):

$$
E T p=(R S / 2450) \cdot(0.025 T+0.08)
$$

where $R S$ is the annual potential solar radiation (KiloJoule) and $T$ is the mean annual temperature.

The annual potential solar radiation was calculated using a specific module implemented in the Grass software GIS (Hofierka $\&$ Súri 2002). This model takes into account solar constant, Earth-Sun distance, solar geometry and incident angles at each location (slope aspect), cast-shadowed and self-shadowed areas, and direct versus diffuse radiation

A slope map and a simplified geological map (scale 1:100.000, Servizio Geologico d'Italia, APAT) were also used. The geological map was a surrogate for pedological information. ARCGIS 9.0 was used to collect, store and manipulate IV as well as environmental data in raster format. The complete list of environmental variables is shown in Tab. 1.

\section{Statistical analysis}

A Regression Tree (RT) and a Stepwise Multiple Linear Regression (MLR) models

Tab. 1 - List of the selected environmental variables.

\begin{tabular}{lc}
\multicolumn{1}{c}{ Environmental variable } & Acronym \\
\hline $\begin{array}{l}\text { Mean Annual Temperature } \\
\text { Mean Maximum Temperature of } \\
\text { the Hottest Month }\end{array}$ & MTH \\
$\begin{array}{l}\text { Mean Minimum Temperature of } \\
\text { the Coldest Month }\end{array}$ & MTC \\
Annual Precipitation & AP \\
Summer Precipitation & SP \\
Winter Precipitation & WP \\
$\begin{array}{l}\text { Moisture Index } \\
\text { Slope }\end{array}$ & Mi \\
Geology: & Slo \\
- Alluvial sediments & - \\
- Arenaceous rocks & \\
- Carbonated rocks & \\
- Clayey formations & \\
- Sands & \\
- Volcanic rocks & \\
\hline
\end{tabular}



tionship between environmental factors and the species abundance. The theory of MLR is quite well known and will not be reported here (interested readers should refer to Neter \& Wasserman 1985). RT models have been widely used in the last few years to study the potential distribution of tree species abundance in the eastern United States (Iverson \& Prasad 1998, Iverson \& Prasad 2002, Iverson et al. 1999). They are based on a recursive data partitioning algorithm that splits the data into subsets based on a single, best predictor variable. The algorithm proceeds by splitting these subsets using the remaining covariate values. The output is a tree with branches and terminal nodes (Fig. 3). The predicted value at each terminal node is the average at that node, which can be considered as relatively homogeneous. Thus, the substantial difference between regression trees and linear regression models is in the effects of the adopted covariates set. In the latter case, the effect is linear and constant over the whole range of covariate values. In the former, the effect of the covariates is neither linear nor constant, producing a categorization of the (quantitative) covariate best predicting the observed response. Moreover, the obtained hierarchical structure gives a simple and effective way to understand the covariates' impact on the observed response; the corresponding role in terms of response prediction can be based on the ordering produced by the increase in the percentage of response variability which is accounted for by each split. The interested were compared in order to quantify the rela-

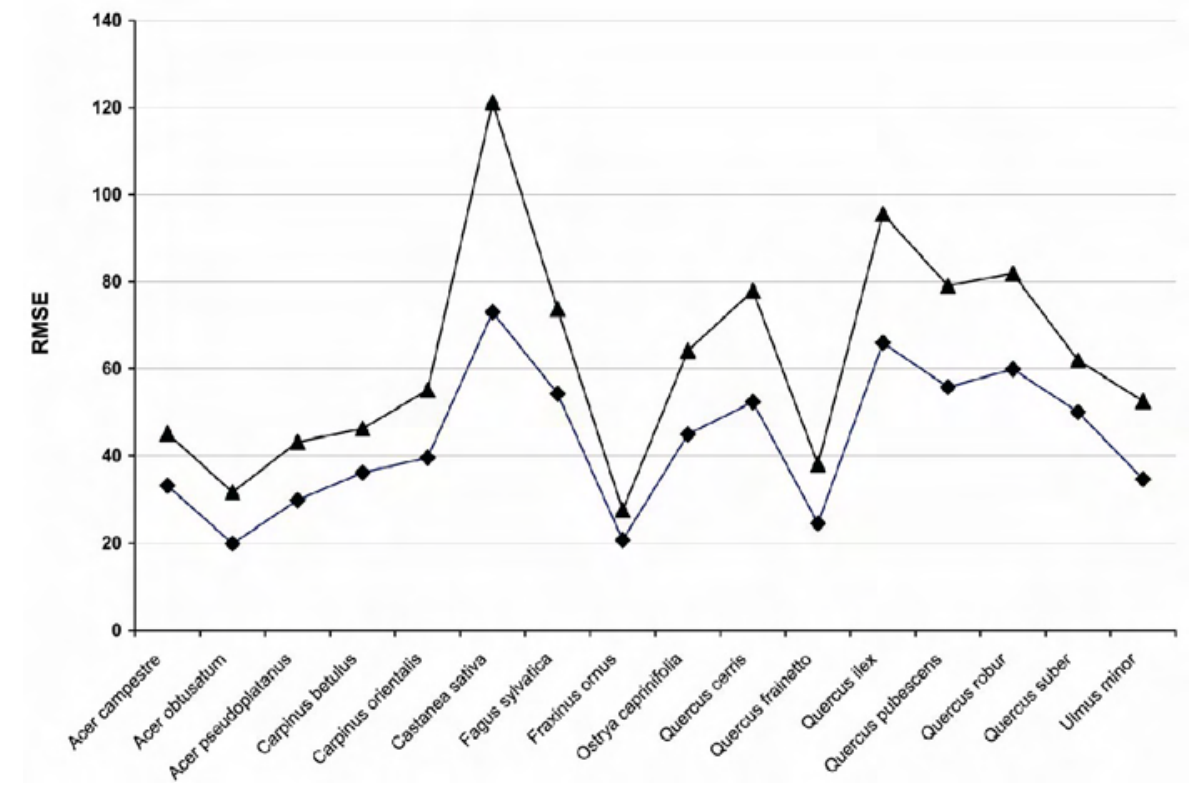

Fig. 2 - Comparison between the RMSE value of the regression tree analysis (black diamonds) and that of the multiple linear regression (black triangles) for all the species.

reader should refer to Breiman et al. (1984). We estimated both models using S-PLUS (Statistical Sciences 1993) considering the species IV as the response variable and the environmental covariates listed in Tab. 1. The RTA model was generated after pruning the full tree.

We randomly put aside $30 \%$ of the data (test set), and trained the models on the remaining $70 \%$ (training set). The RTA and the MLR were evaluated on the test set using

Tab. 2 - Validation of the regression tree model. $\mathrm{N}$ is the number of sample plots. $\mathrm{R}$ is the correlation between measured and predicted IV. OA_Ve and OA_Va are the omission accuracy for the whole data set (verification) and for the $30 \%$ of the validation data set respectively. Abbreviations for chorology: M, Mediterranean; SM, Sub-Mediterranean; E, Eurosiberian.

\begin{tabular}{lcrccc}
\hline \multicolumn{1}{c}{ Species } & Chorology type & N & R & OA_Ve & OA_Va \\
\hline Quercus ilex & M & 102 & 0.77 & 0.79 & 0.68 \\
Quercus suber & M & 43 & 0.63 & 0.77 & 0.67 \\
Mean & - & - & 0.70 & 0.78 & 0.68 \\
Acer campestre & SM & 106 & 0.72 & 0.67 & 0.65 \\
Acer obtusatum & SM & 85 & 0.63 & 0.85 & 0.74 \\
Carpinus orientalis & SM & 54 & 0.53 & 0.63 & 0.61 \\
Castanea sativa & SM & 85 & 0.78 & 0.89 & 0.85 \\
Fraxinus ornus & SM & 141 & 0.63 & 0.76 & 0.68 \\
Ostrya carpinifolia & SM & 177 & 0.74 & 0.81 & 0.75 \\
Quercus cerris & SM & 287 & 0.81 & 0.97 & 0.92 \\
Quercus frainetto & SM & 41 & 0.60 & 0.82 & 0.71 \\
Quercus pubescens & SM & 361 & 0.80 & 0.98 & 0.86 \\
Mean & - & - & 0.69 & 0.82 & 0.75 \\
Acer psedoplatanus & $\mathrm{E}$ & 88 & 0.68 & 0.84 & 0.75 \\
Carpinus betulus & $\mathrm{E}$ & 73 & 0.62 & 0.60 & 0.64 \\
Fagus sylvatica & $\mathrm{E}$ & 263 & 0.90 & 0.99 & 0.95 \\
Quercus robur & $\mathrm{E}$ & 59 & 0.57 & 0.79 & 0.69 \\
Ulmus minor & $\mathrm{E}$ & 50 & 0.76 & 0.70 & 0.72 \\
Mean & - & - & 0.71 & 0.78 & 0.75 \\
\hline
\end{tabular}

the mean RMSE between the current and predicted IVs for each species. The best model was evaluated by calculating both the correlation between current and predicted IV as well as the so-called Omission Accuracy (OA) measure. To calculate this last measure, we categorized the observed and predicted IVs into binary variable indicating if the values were over a certain threshold. The threshold was set at 2 IV since the values below were characterised by a high uncertainty. For each species, the OA formula is $\left(\mathrm{SP} /(\mathrm{SP}+\mathrm{SO})^{*} 100\right)$, where $\mathrm{SP}$ is the number of areas with observed values over the threshold where the species was correctly predicted as present and SO is the number of areas with observed values over the threshold where the species was incorrectly predicted as absent. Because of the sampling approach we used, classification accuracy was not calculated for the test set; indeed, the absence of a species at a given sampling plot does not imply its absence over the $3 \times 3$ km grid.

The results obtained through the final model were used to produce maps of both current and future potential distribution under a scenario of changed climate assuming unlimited dispersal capacity of the species. The predicted potential distribution was obtained by replacing the climate variables with those obtained from the HadCM3 GCM; predicted values were then imported into ArcGIS to produce the corresponding maps.

The effects of climate change on species distribution were evaluated by calculating the percentage changes in the potential area as well as on the mean IV and altitude. 

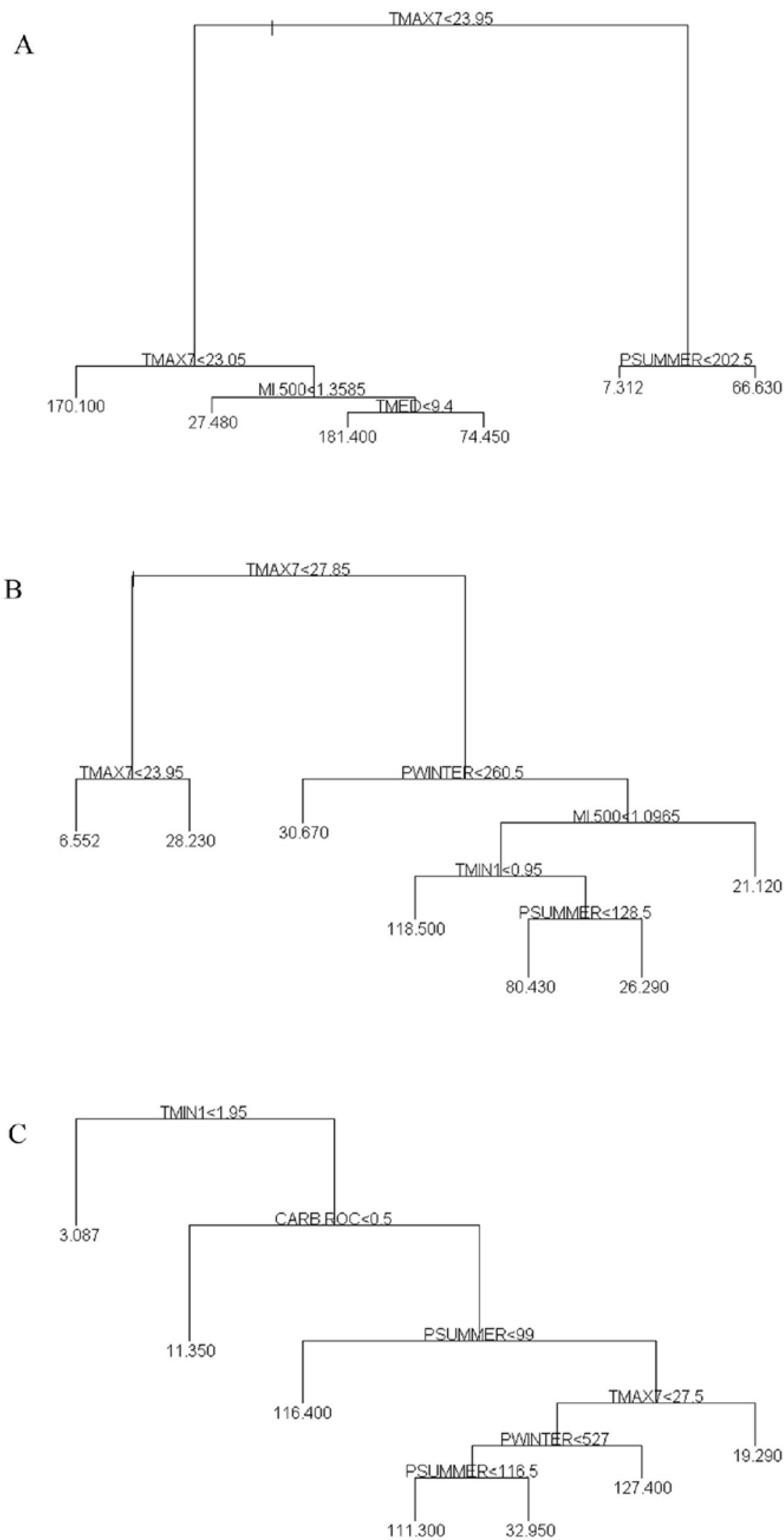

Fig. 3 - Tree diagrams for A - Fagus sylvatica, B - Quercus cerris, C - Quercus ilex. The abundance of each variable is proportional to the length of the corresponding couple of branches. The numbers at the termination of each node of the tree show the average IV at that node.

\section{Results}

Comparison and evaluation of models The comparison between RMSE values corresponding to both models for all of the analysed species shows that RTA always outperformed MLR, in terms of predicting species distribution for the training set (Fig. 2). For this reason, RTA was chosen as the best method; the corresponding performance measures are reported in Tab. 2. The number of plots for each species used for the modelling process is a measure of the abundance of the species within the study area. Quercus pubescens and Quercus cerris were the most widespread species, respectively with 361 and 287 plots. These were followed by Fagus sylvatica (263 plots). In contrast, Quercus frainetto and Quercus suber, the rarest species, were limited to the coastal areas characterised by acidic soils (Attorre \& Bruno 2003). The correlation between observed and predicted IV values ranged between 0.53 of Carpinus orientalis to 0.90 of Fagus sylvatica. Predicted current distributions match well the inventory data for almost all the species, with Fagus sylvatica, Quercus pubescens and Quercus cerris showing the highest omission accuracy values in both the verification and the validation data set. Only three species, Carpinus orientalis, Carpinus betulus and Acer campestre had values of omission accuracy index below $70 \%$.

\section{Environmental correlates of tree species abundance}

The tree diagrams produced by RTA analysis are shown in Fig. 3a for a Eurosiberian species (Fagus sylvatica), in Fig. 3b for a Sub-Mediterranean species (Quercus cerris) and in Fig. 3c for a Mediterranean one (Quercus ilex). As aforementioned, the tree diagrams proved to be a useful way to highlight the interactions between environmental variables and species distribution (Iverson \& Prasad 1998, Vayssières et al. 2000, Thuiller et al. 2003). The length of tree diagram branches is proportional to the variance explained by the current split. The terminal nodes of the data set indicate the average IV value for the relatively homogeneous subset. Fagus sylvatica is mainly found in areas with an average temperature of less than 24 ${ }^{\circ} \mathrm{C}$ for the hottest month. In areas above this climatic limit, the species can only be found in very small areas characterised by a high amount of summer precipitation (above 200 $\mathrm{mm})$. In fact, in those areas, it is still possible to find remnant patches of Fagus sylvatica, residual of previous cycles of expansion of the species (Magri 1998). The maximum temperature of the hottest month is also the most important variable for Quercus cerris, one of the most widespread species in the area. In this case the species has a 
threshold of $27.8{ }^{\circ} \mathrm{C}$, above which it can be found only in areas characterised by high winter precipitation $(>260 \mathrm{~mm})$, excluding the hyper humid areas (moisture index values $>1$ ). In contrast, the average minimum temperature the most important variable in influencing the spatial distribution of Quercus ilex. In fact, the species is absent in areas characterised by very low winter temperature (MTC $<2{ }^{\circ} \mathrm{C}$ ). The other important variables are: the presence of a geological substratum of carbonated rocks and summer aridity, since the species is well adapted to these conditions.

\section{Potential current and future distribution} of tree species abundance

According to the estimated model, Quercus pubescens and Quercus cerris are the species with the widest potential distribution (Tab. 3). Fagus sylvatica and Castanea sativa have a smaller potential area, but they also have a high average IV, 83.5 and 60.9 respectively. This means that these two species tend to form almost mono-specific forests. Instead, Quercus frainetto and Acer pseudoplatanus have the smallest potentiality in terms both of area and IV. Generally they are associated, respectively, with Quercus cerris and Fagus sylvatica. Once we had established a reasonably reliable (in terms of RMSE) model for all the species, current climatic data were replaced with those obtained through HadCM3 GCM in order to evaluate potential future distribution. The prediction of potential species distribution shows significant changes for many species: there is a general trend towards an increasing mean altitude, with the exception of Fraxinus

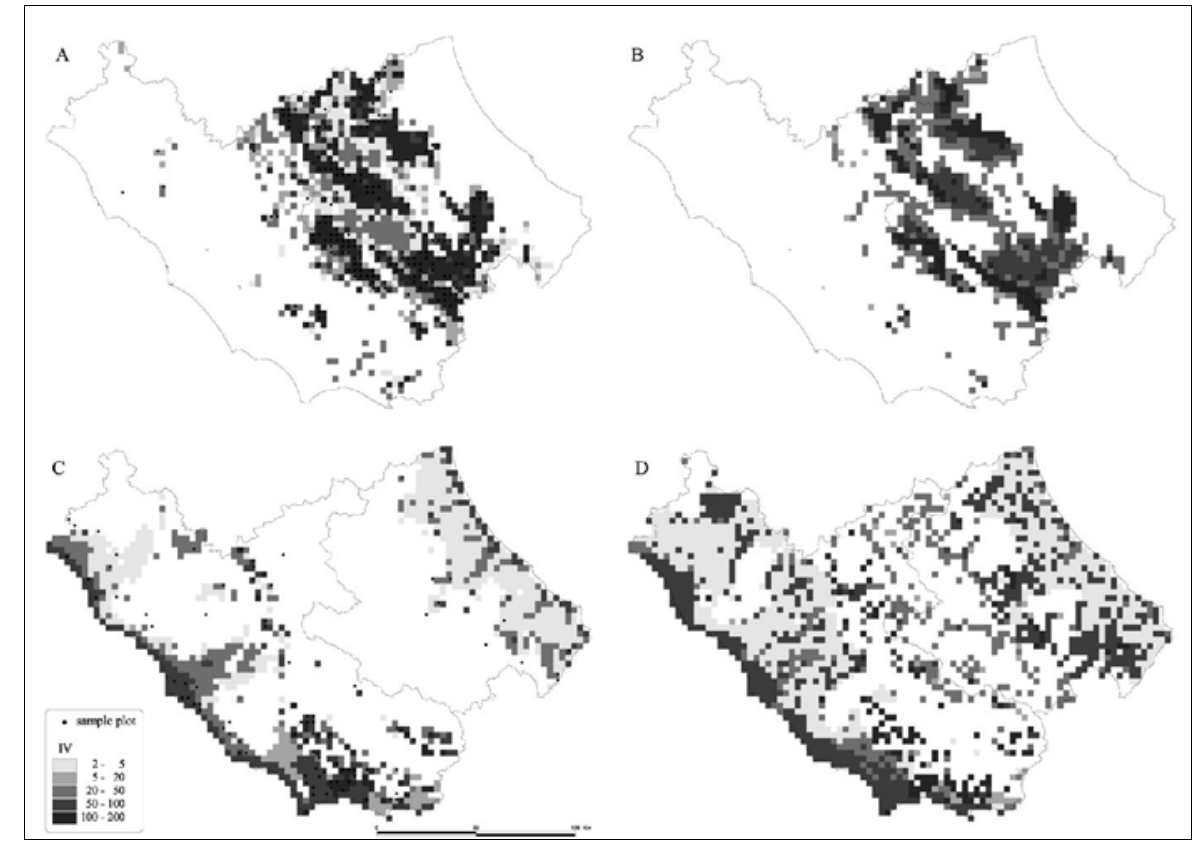

Fig. 4 - Current and future predicted potential distribution of Fagus sylvatica (A, B) and Quercus ilex (C, D).

ornus. Five species should increase both their area and IV (Group 1, Tab. 2), while six species should reduce both these parameters. Moreover, Acer campestre and Carpinus betulus present an increasing area and a decreasing IV, while Carpinus orientalis, Fraxinus ornus and Quercus frainetto show an opposite trend. As an example, the maps of the current potential and future potential distribution of four species belonging to the four different groups identi-

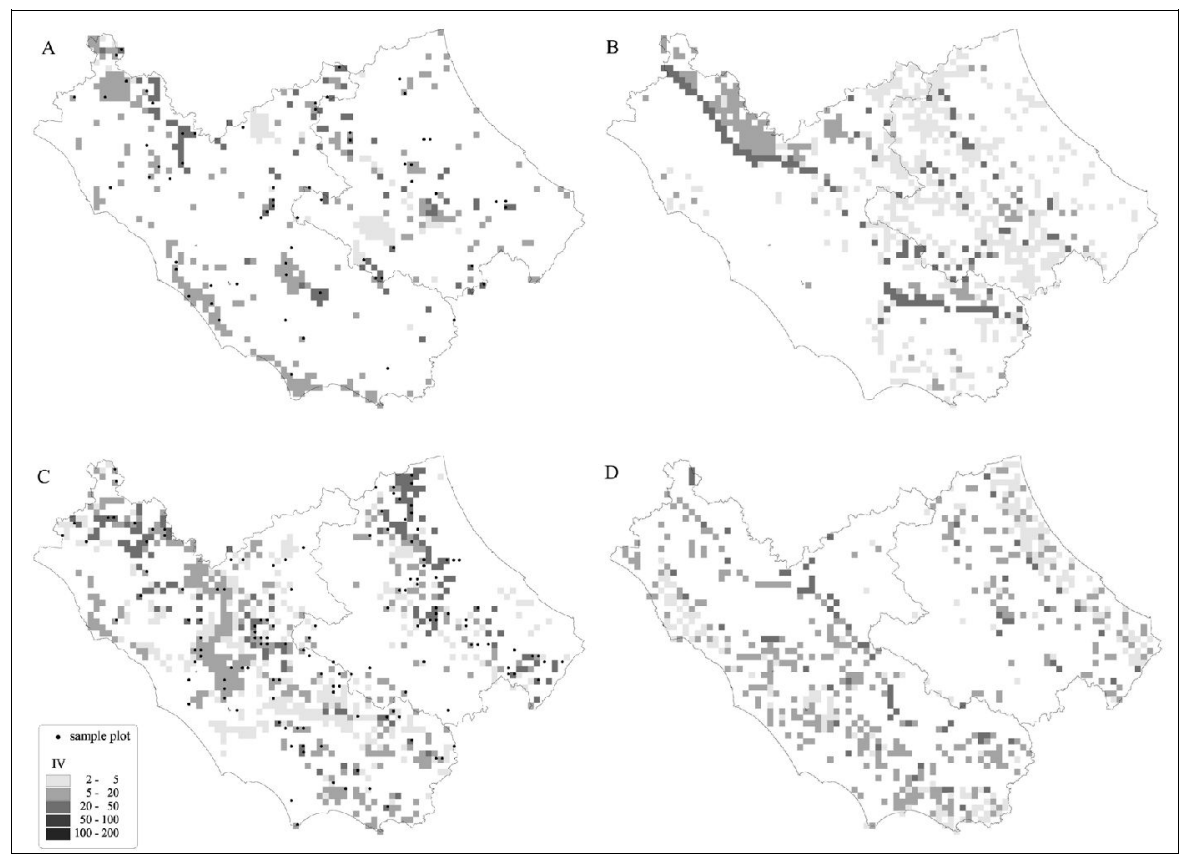

Fig. 5 - Current and future predicted potential distribution of Carpinus betulus (A, B) and Fraxinus ornus (C, D). fied in relation to their response to changes in the climatic scenario are shown in Fig. 4 and Fig. 5. The two well-modelled species (Fagus sylvatica and Quercus ilex) show a good correspondence between the distribution of sample plots and the predictions (Fig. 4), while the two fairly-modelled species (Fraxinus ornus and Carpinus betulus) show a higher number of incorrectly predicted "absent" plots (Fig. 5). The application of the climate scenario determines a noticeable reduction of area and IV of Fagus sylvatica (respectively - 29\% and -3\%), the expansion of Quercus ilex (Area $+74.6 \%$, IV $+2.4 \%$ ), the transformation of Carpinus betulus from the status of sporadic, localised extra-zonal species to that of a more widespread species in the submountain areas as shown by the increase of area $(+81.5 \%)$ and average altitude (+94.9), and the strong reduction in area of Fraxinus ornus area $(-20 \%)$ and a contemporaneous increase of its IV (+2.2 - Tab. 3).

\section{Discussion}

\section{Model comparison}

RTA had a better performance in modelling the spatial distribution of all the analysed species compared to MLR (Fig. 2). This result can be explained since RTA neither relies on linearity of covariate effects nor on constant effects throughout the analysed area. This could mean that RTA could readily accommodate departures from a homogeneous model, accounting for local discontinuities as well as for local dependencies. These differences in model features are substantial if the observed species distribu- 
Tab. 3 - Current, future and percentage of change of the potential area $\left(\mathrm{km}^{2}\right)$ and average IV and altitude (m); the percentage changes are due to the HadCM3 model outputs; Ellenberg's scores for temperature (T) and moisture (M). In the last columns, X means the species has a wide spectrum for that parameter. Abbreviations for chorology: M, Mediterranean; SM, Sub-Mediterranean; E, Eurosiberian.

\begin{tabular}{|c|c|c|c|c|c|c|c|c|c|c|c|c|c|}
\hline \multirow{2}{*}{ Group } & \multirow{2}{*}{ Species } & \multirow{2}{*}{$\begin{array}{c}\text { Choro- } \\
\text { logy } \\
\text { type }\end{array}$} & \multicolumn{3}{|c|}{ Area $\left(\mathbf{k m}^{2}\right)$} & \multicolumn{3}{|c|}{ IV } & \multicolumn{3}{|c|}{ Altitude (m) } & \multirow{2}{*}{$\mathbf{T}$} & \multirow{2}{*}{$\mathbf{M}$} \\
\hline & & & Current & Future & $\%$ & Current & Future & $\%$ & Current & Future & $\%$ & & \\
\hline \multirow{5}{*}{$\begin{array}{l}\text { Group 1: } \\
+I V+\text { Area }\end{array}$} & Quercus cerris & SM & 24417 & 24832 & 1.7 & 46 & 67.3 & 46.3 & 408.3 & 576.1 & 41.1 & 8 & 4 \\
\hline & Quercus ilex & M & 9423 & 16453 & 74.6 & 37 & 37.9 & 2.4 & 212.4 & 342 & 61 & 9 & 3 \\
\hline & Quercus pubescens & SM & 24732 & 27947 & 13 & 60.7 & 81.7 & 34.6 & 414.3 & 541.5 & 30.7 & 8 & 3 \\
\hline & Quercus suber & $\mathrm{M}$ & 3006 & 5282 & 75.7 & 40.7 & 48.1 & 18.2 & 75.2 & 79.3 & 5.5 & 8 & 3 \\
\hline & Ulmus minor & $\mathrm{E}$ & 2682 & 2926 & 9.1 & 24.9 & 33.4 & 34.1 & 163.2 & 216.6 & 32.7 & 7 & $\mathrm{X}$ \\
\hline \multirow{6}{*}{$\begin{array}{l}\text { Group 2: } \\
\text {-IV-Area }\end{array}$} & Acer obtusatum & SM & 3393 & 1863 & -45.1 & 13.4 & 11.6 & -13.4 & 698.6 & 1159 & 65.9 & 5 & 6 \\
\hline & Acer pseudoplatanus & $\mathrm{E}$ & 2115 & 584 & -72.4 & 12.7 & 10.6 & -16.5 & 972.7 & 1297.6 & 33.4 & 5 & 6 \\
\hline & Castanea sativa & SM & 5175 & 5051 & -2.4 & 60.9 & 38.4 & -36.9 & 578.2 & 932.6 & 61.3 & 8 & $\mathrm{X}$ \\
\hline & Fagus sylvatica & $\mathrm{E}$ & 8946 & 6352 & -29 & 83.5 & 81 & -3 & 1144.2 & 1330.7 & 16.3 & 5 & 5 \\
\hline & Ostrya caprinifolia & SM & 7497 & 4183 & -44.2 & 24.8 & 23 & -7.3 & 736.5 & 1082.7 & 47 & 8 & 4 \\
\hline & Quercus robur & $\mathrm{E}$ & 5634 & 3747 & -33.5 & 28.9 & 21.7 & -24.9 & 238.2 & 248.2 & 4.2 & 6 & 6 \\
\hline \multirow{2}{*}{$\begin{array}{l}\text { Group 3: } \\
\text {-IV+Area }\end{array}$} & Acer campestre & SM & 6255 & 7400 & 18.3 & 25.3 & 18.5 & -26.9 & 330.5 & 358.3 & 8.4 & 7 & 5 \\
\hline & Carpinus betulus & $\mathrm{E}$ & 3645 & 6616 & 81.5 & 14.7 & 8.1 & -44.9 & 442.7 & 862.8 & 94.9 & 6 & $\mathrm{X}$ \\
\hline \multirow{3}{*}{$\begin{array}{l}\text { Group 4: } \\
+I V-A r e a\end{array}$} & Carpinus orientalis & SM & 1242 & 532 & -57.2 & 18.2 & 30.9 & 69.8 & 616.8 & 1244.1 & 101.7 & 7 & 3 \\
\hline & Fraxinus ornus & SM & 7101 & 5681 & -20 & 13.4 & 13.7 & 2.2 & 468.6 & 380 & -18.9 & 8 & 3 \\
\hline & Quercus frainetto & SM & 3645 & 2278 & -37.5 & 12.8 & 21.7 & 69.5 & 63.7 & 79.8 & 25.3 & 6 & 6 \\
\hline
\end{tabular}

tion is highly scattered and potentially heteroscedastic, with local hotspots and wide areas with non-relevant IV values.

Actual and potential current distribution of tree species abundance

Using results from RTA, a significant correlation between number of sample plots where the species was recorded and model accuracy was found (Tab. 2). Indeed, species whose distribution is more strongly linked to local climatic conditions (Quercus pubescens, Quercus cerris and Fagus sylvat$i c a)$ show a higher accuracy in model predictions. Instead, rare species (mainly extrazonal), being at the edge of their distribution or having more specific habitat requirements, were less accurately modelled (e.g., Carpinus orientalis and Carpinus betulus).

The main chorological component was represented by Sub-Mediterranean deciduous species (8 species), showing on average the best accuracy values (Tab. 2). The second group was formed by Eurosiberian species (6), while only two Mediterranean evergreen sclerophyllous species have a spatial distribution wide enough to be included in this analysis: Quercus ilex and Quercus suber. Species belonging to the same chorological type and thus sharing the same geographical distribution have different capacities of adaptation to local conditions. For this reason a
Eurosiberian species such as Fagus sylvatica has, in the study area, a wide distribution well modelled by this climatic model, while Carpinus betulus, also Eurosiberian, is more localized, dependent on factors other than the climatic ones and fairly modelled.

The deciduous tree species are more abundant than the sclerophyllous evergreen ones in terms of species number and spatial distribution. This result depends on the fact that the study area, despite its Mediterranean location, is characterized mainly by a temperate climate because of the effects of the Apennine mountains, which intercept the humid winds from the sea, thus causing a rainfall increase (Attorre et al. 2007). Moreover, in this area, the dominance of deciduous species has characterised almost all of the interglacial periods during the last 250000 years (Follieri et al. 1993). As shown by the analysis of lake sediments, during the Holocene a progressive increase of pollen of sclerophyllous tree species, mainly Quercus ilex, did occur starting from 1.500 B.C. This change can neither be explained by climate change nor by the use of fire to clear land for agriculture (Magri 1994). For this reason, it may be hypothesized the occurrence of the same process recorded in southern France (Romane \& Terradas 1992): the prolonged exploitation of forests caused increasing soil erosion, especially in the southern exposures of the Apennine mountains, favouring Quercus ilex, which is more adapted to xeric environments than deciduous species such as Quercus pubescens and Quercus cerris. This hypothesis may also explain the current presence of areas with potentially high IV in the inner part of the Lazio region (see Fig. 4c).

Other examples of tree species expansion due to human intervention are those of Castanea sativa for timber and food production dating back to the Greco-Roman age and the more recent example of Quercus suber in the western side of the Italian peninsula for the production of cork (ScarasciaMugnozza et al. 2000). Those examples are, however, the exception in a general framework, where a general reduction of the distribution of tree species has occurred after the post-glacial recolonisation as a result of deforestation and land use changes (Quézel 1993). This process was not continuous and ceaseless, depending on the historical socioeconomic conditions: as an example, the secondary recolonization of the mountain Apennine pastures by Fagus sylvatica occurred during the last decades due to the reduction of traditional breeding activities (Attorre \& Bruno 2003).

\section{Future potential distribution}

A general increase of the average potential altitude is predicted applying the HADCM3 
climate scenario for year 2080. However if area and abundance are analysed, four different trends can be identified: species that could be advantaged by the predicted climate change (Tab. 3, group 1), species that could suffer a strong reduction of area and abundance (Group 2) and species showing contrasting behaviour in relation to area and abundance (Group 3, 4).

According to the chorological types, the two Mediterranean species (Quercus ilex and Quercus suber) are likely to be favoured by the predicted increased drought, while the species belonging to the two other chorological types show quite differentiated behaviour. According to the Ellenberg's scores, the more thermophilous and xerophilous species should be favoured by the predicted drought (Group 1, Tab. 3). In contrast, mesophilous species should suffer a strong reduction of area and abundance (Group 2). For the two remaining groups, there is not a clear ecological explanation for their particular trends. However, it should be noticed that they are formed by fairly modelled species, such as Carpinus orientalis, Carpinus betulus and Quercus frainetto. Indeed, the above species are at the edge of their natural range, so it may be hypothesized that their presence in the study area is linked to other variables (e.g., edaphic factors) not included in the model. On the other hand, Acer campestre and Fraxinus ornus are low-frequency species spread over different plant communities, so a better definition of their climatic niche is expected to be obtained by enlarging the study area.

\section{Conclusions}

RTA has proven to be efficient for the identification of the environmental variables driving the current distribution and abundance of tree species at a regional scale. Only Mediterranean species are likely to be favoured by the predicted climate change, while for the two other chorological types (Sub-Mediterranean and Eurosiberian) the response seems to be species-specific depending on the autoecological characteristic of each species. A more complete picture of the potential effects of climate change would be obtained by analysing the whole Italian peninsula considered as a biogeographical unit and including a detailed land use map as a measure of fragmentation and anthropization of the territory, influencing the expected shift of species.

\section{Acknowledgements}

This work has been carried out in the framework of CONECOFOR (CONtrollo ECOsistemi FORestali), the intensive monitoring programme of forest ecosystems in Italy. The programme is framed within the Pan-European Level II Monitoring of Forest Ecosystems. It is co-sponsored by the
European Union under the Regulation no. 2152/2003 "Forest Focus" and co-operate with the UN/ECE ICP-Forests and the UN/ECE ICP-Integrated Monitoring of Ecosystems. CONECOFOR is managed by Corpo Forestale dello Stato, Divisione $6^{\mathrm{a}}$, CONECOFOR Board, acting also as National Focal Center (NFC) of Italy within the EU and UN/ECE programmes.

\section{References}

Allavena S, Isopi R, Petriccione B, Pompei E (2000). Programma Nazionale Integrato per il controllo degli ecosistemi forestali. Secondo rapporto 2000. Ministero per le politiche agricole (Roma).

Araújo MB, Cabeza M, Thuiller W, Hannah L, Williams PH (2004). Would climate change drive species out of reserves? An assessment of existing reserve selection methods. Global Change Biology 10: 1618-1626.

Attorre F, Bruno F (2003). Processi di riforestazione naturale della faggeta nella fascia altitudinale inferiore del verante laziale del Massiccio dei Monti Simbruini (Italia centrale). Fitosociologia 40: 55-71.

Attorre F, Alfò M, De Sanctis M, Francesconi F, Bruno F (2007). Comparison of interpolation methods for mapping climatic and bioclimatic variables at regional scale. International Journal of Climatology 27 (13): 1825-1843.

Bakkenes M, Alkemade RM, Ihle, Leemans R, Latour JB (2002). Assessing effects of forecasted climate change on the diversity and distribution of European higher plants for 2050. Global Change Biology 8: 390-407.

Berry PM, Dawson TE, Harrison PA, Pearson RG (2002). Modelling potential impacts of climate change on the bioclimatic envelope of species in Britain and Ireland. Global Ecology and Biogeography 11: 453-462.

Breiman L, Friedman JH, Olshen RA, Stone CJ (1984). Classification and Regression Trees. Chapman \& Hall, New York, USA.

Ellenberg H, Weber HE, Düll R, Wirth V, Werner V (1992). Zeigerwerte von Pflanzen in Mitteleuropa ( $2^{\text {nd }}$ edn.). Scripta Geobotanica 18: 1-258.

FAO (2001). Global forest resources assessment 2000. Main report. Food and Agriculture Organization of the United Nations, Rome.

Falcucci A, Maiorano L, Boitani L (2007). Changes in land-use/land-cover patterns in Italy and their implications for biodiversity conservation. Landscape Ecology 22: 617-631.

Follieri M, Magri D, Narcisis B (1993). Paleoenvironmetal investigations on long sediment cores from volcanic lakes of Lazio (central Italy) - An overview. In: "Paleoelimnology of European Maar Lakes" (Negendank JFW, Zolitschka B eds). Springer, Berlin, pp 95-107.

Guisan A, Zimmermann NE (2000). Predictive habitat distribution models in ecology. Ecological Modelling 135:147-186.

Hampe A (2004). Bioclimate envelope models: what they detect and what they hide. Global Ecology and Biogeography 13: 469- 471.
Hofierka J, Súri M (2002). The solar radiation model for Open source GIS: implementation and applications. Open source GIS - GRASS users conference, Trento, Italy.

Iverson LR, Prasad A (1998). Predicting abundance for 80 tree species following climate change in the Eastern United States. Ecological Monographs 68: 465-485.

Iverson LR, Prasad A (2002). Potential redistribution of tree species habitat under five climate change scenarios in the eastern US. Forest Ecology and Management 155: 205-222.

Iverson LR, Prasad A, Schwartz MK (1999). Modelling potential future individual tree-species distributions in the eastern United States under a climate change scenario: a case study with Pinus virginiana. Ecological Modelling 115: 77-93.

Jensen ME, Haise HR (1963). Estimating evapotranspiration from solar radiation. Journal of the Irrigation and Drainage Division 89: 15-41.

Magri D (1994). Late-Quaternary changes of plant biomass as recorded by pollen-stratrigraphical data: a discussion of the problem at Valle Castiglione, Italy. Review of Paleobotany and Palynology 81: 311-323.

Magri D (1998). Quaternary history of Fagus in the Italian peninsula. Annali di Botanica 56: 147-154.

Malcolm JR, Cancan L, Neilson RP, Hansen L, Hannah L (2006). Global warming and extinctions of endemic species from biodiversity hotspots. Conservation Biology 20: 538-548.

Midgley GF, Hannah L, Millar D, Rutherford MC, Powrie LW (2002). Assessing the vulnerability of species richness to anthropogenic climate change in a biodiversity hotspot. Global Ecology and Biogeography 11: 445-451.

Mitasova H, Mitas L (1993). Interpolation by regularized spline with tension: theory and implementation. Mathematical Geology 25: 641-655.

Mitchell T, Carter TR, Jones P, Hulme M, New M (2004). A comprehensive set of high-resolution grids of monthly climate for Europe and the globe: observed record (1901-2000) and 16 scenarios (2001-2100). Tyndall Centre for Climate Change Research, Working Paper no. 55.

Nakicenovic N, Swart R (2000). Emissions scenarios. Special report of Working Group III of the Intergovernmental Panel on Climate Change. Cambridge University Press, Cambridge, UK.

Neter J, Wasserman W (1985). Applied Linear Statistical Models, Irwin, Boston, MA, USA. Ohlemüller R, Gritti ES, Sykes MT, Thomas CD (2006). Quantifying components of risk for European woody species under climate change. Global Change Biology 12: 1788-1799.

Parmesan C, Yohe G (2003). A globally coherent fingerprint of climate change impacts across natural systems. Nature 421: 37-42.

Pearson RG, Dawson TE (2003). Predicting the impacts of climate change on the distribution of species: are bioclimate envelope models useful? Global Ecology and Biogeography 12: 361-371.

Pearson RG, Dawson TP, Berry PM, Harrison PA (2002). SPECIES: a spatial evaluation of climate impact on the envelope of species. Ecological 
Modelling 154: 289-300.

Pignatti S (1982). Flora d'Italia (vol. 1-3). Edagricole.

Pignatti S (2005). Bioindicator values of vascular plants of the Flora of Italy. Braun-Blanquetia 39: 3-95.

Quézel P (1993). Definition of the Mediterranean region and origin of its flora. In: "Plant Conservation in the Mediterranean Area" (GomezCampo C ed). W. Junk, Dordrecht, NL, pp. 9-24. Romane F, Terradas J (1992). Quercus ilex ecosystems: function, dynamics and management Kluwer Publ., Dordrecht, NL, pp. 380.

Root TL, Price JT, Hall KR, Schneider SH, Rosenzweig C, Pounds JA (2003). Fingerprints of global warming on wild animals and plants. Nature 421: 57-60.

Scarascia-Mugnozza G, Oswaldb H, Piussi P Radoglou K (2000). Forests of the Mediterranean region: gaps in knowledge and research needs. Forest Ecology and Management 132: 97-109.

Segurado P, Araújo MB (2004). An evaluation of methods for modelling species distributions. Journal of Biogeography 31: 1555-1568.

Skov F, Svenning JC (2004). Potential impact of climatic change on the distribution of forest herbs in Europe. Ecography 27: 366-380.

Statistical Sciences (1993). S-PLUS: Guide to statistical and mathematical analysis. Statistical Sciences, Seattle, WA, USA.

Thomas CD, Cameron A, Green RE, Bakkenes M, Beaumont LJ, Collingham YC, Erasmus BFN, Ferreira de Siqueira M, Grainger A, Hannah L, Hughes L, Huntley B, van Jaarsveld AS, Midgley GF, Miles L, Ortega-Huerta MA, Peterson AT, Phillips OL, Williams SE (2004). Extinction risk from climate change. Nature 427: 145-148.

Thuiller W (2003). BIOMOD - optimizing predictions of species distribution and projecting potential future shifts under global change. Global Change Biology 9: 1353-1362.

Thuiller W (2004). Patterns and uncertainties of species' range shifts under climate change. Glob- al Change Biology 10: 2020-2027.

Thuiller W, Araùjo MB, Pearson RG, Whittaker RJ, Brotons L, Lavorel S (2004). Uncertainty in predictions of extinction risk. Nature 430: 30. Thuiller W, Lavorel S, Araùjo MB (2005). Niche properties and geographic extent as predictors of species sensitivity to climate change. Global Ecology and Biogeography 14: 347-357.

Thuiller W, Midgely GF, Hughes GO, Bomhard B, Drew G, Rutherford MC, Woodward FI (2006). Endemic species and ecosystem sensitivity to climate change in Namibia. Global Change Biology 12: 1-18.

Thuiller W, Vayreda J, Pino J, Sabate S, Lavorel S, Gracia C (2003). Large-scale environmental correlates of forest tree distributions in Catalonia (NE Spain). Global Ecology and Biogeography 12: 313-325.

Vayssières MP, Plant RE, Allen-Diaz BH (2000). Classification trees: an alternative non-parametric approach for predicting species distributions. Journal of Vegetation Science 11: 679-694. 